\title{
Treatment of squamous cell and adenocarcinoma of the esophagus
}

This article was published in the following Dove Press journal:

Gastrointestinal Cancer:Targets and Therapy

12 November 2012

Number of times this article has been viewed

\section{Barrie Rathbone' Janusz Jankowski Michael Rathbone ${ }^{3}$ \\ 'University Hospitals of Leicester, Leicester, ${ }^{2}$ Sir James Black Professor Queen Mary University of London, ${ }^{3}$ St George's University of London, London, United Kingdom}

\begin{abstract}
Esophageal cancer is the sixth commonest cause of cancer death worldwide. It predominantly occurs in two histological types, ie, squamous cell carcinoma and adenocarcinoma, each with its own distinct geographical distribution and natural history. The incidence of esophageal adenocarcinoma is rising, as is that of its precursor lesion, Barrett's esophagus, which consists of metaplastic change in the squamous mucosa of the esophagus in response to damage by gastroesophageal reflux disease. The principal risk factors for esophageal cancer are cigarette smoking and alcohol consumption, reflux disease, and obesity. In tumors without local invasion or distant metastases, surgery remains the treatment option of choice, although there are considerable differences of opinion regarding the roles of chemotherapy and radiotherapy. A wide variety of endoscopic treatments are available for dysplastic lesions and palliation. Despite the availability of increasingly complex imaging modalities and expensive and possibly ineffective attempts at screening, the evidence base is conflicted and the prognosis remains poor. However, from a recent large systematic review, three clear recommendations can be made, ie, use of endoscopic resection for high grade dysplasia, use of radiofrequency ablation for residual premalignant lesions, and, finally, prevention of risk factors for cancer, such as smoking, alcohol consumption, and obesity.
\end{abstract}

Keywords: cancer, Barrett's, esophagus, squamous cell carcinoma, adenocarcinoma

\section{Introduction}

The recent onset of dysphagia for solids in an otherwise fit elderly man is the all too common presentation of esophageal cancer, which is more than likely to be locally advanced at the time of diagnosis and hence incurable. This remains the unfortunate reality for most of our patients with esophageal cancer.

Esophageal cancer is the sixth most common cause of cancer death worldwide. ${ }^{1}$ What we term loosely as esophageal cancer refers for the most part to two histologically distinct malignancies, ie, esophageal adenocarcinoma and esophageal squamous cell carcinoma. The two entities are usually discussed together, particularly in terms of treatment, but do differ in etiology, pathogenesis, and response to treatment. Tumors in the lower esophagus are more likely to be adenocarcinomas, whereas tumors in the upper esophagus are more likely to be squamous carcinomas with lymph node involvement. While squamous tumors have been decreasing, esophageal adenocarcinomas represent the only gastrointestinal tract tumor increasing in incidence.
Correspondence: Barrie Rathbone University Hospitals of Leicester, Leicester, UK

Tel +44 II 62586630

Fax +44 II62 586985

Email barrie.rathbone@uhl-tr.nhs.uk 


\section{Epidemiology}

In 2008, an estimate of new esophageal cancer cases reported 482,300 cases and 406,800 deaths worldwide. ${ }^{2}$ The incidence of esophageal cancer varies considerably across the world. Particularly high rates are seen in northern Iran, southern Russia, northern China, and southern and eastern Africa. ${ }^{3}$ The lowest rates are seen in western and middle Africa and central America. The geographical distribution has a similar pattern for men and women although the risk of developing esophageal cancer is three to four times greater in men. ${ }^{2}$

Esophageal cancer can occur in a variety of histological types, but the vast majority is either squamous cell carcinoma or adenocarcinoma. In high risk areas, the commonest cancer is squamous cell carcinoma, but in lower risk areas such as the UK and the US, adenocarcinoma has overtaken squamous cell carcinoma in incidence rates. This change appears to be related to a true increase in the incidence of esophageal adenocarcinoma. ${ }^{4}$

\section{Etiology}

There are several well established risk factors for the development of esophageal cancer, increasing the likelihood of adenocarcinoma or squamous cell carcinoma or both. The key etiological factors can be divided into those to do with lifestyle, predisposing illness, nutritional deficiencies, and lower socioeconomic status.

The major implicated lifestyle factors are tobacco smoking and alcohol consumption. A recent prospective cohort study from The Netherlands demonstrated an increased risk of esophageal squamous cell carcinoma and esophageal adenocarcinoma associated with cigarette smoking. ${ }^{5}$ Alcohol was associated with an increased risk of esophageal squamous cell carcinoma, but not with esophageal adenocarcinoma. Alcohol and smoking together appeared to have a synergistic effect in the development of esophageal squamous cell carcinoma.

Predisposing conditions causing esophageal stasis or gastro-esophageal reflux predispose to esophageal cancer. Achalasia where there is a hypertonic lower esophageal sphincter and loss of body peristalsis resulting in esophageal stasis has been shown to increase the risk of both esophageal adenocarcinoma and squamous cell carcinoma. ${ }^{6}$ Simple reflux disease and its predisposing conditions, such as obesity and hiatus hernia, have been demonstrated to cause a modest increase in the risk of esophageal adenocarcinoma. ${ }^{7}$ Of more significance in terms of risk is the reflux-related condition, Barrett's esophagus.

Barrett's esophagus was originally described in $1950{ }^{8}$ It represents metaplastic change occurring in the esophageal squamous mucosa in response to reflux damage. The components of Barrett's esophagus are replacement of the normal squamous lining with columnar epithelium containing specialized intestinal metaplasia. The prevalence of Barrett's in the population is $2 \%$, affecting men twice as often as women. ${ }^{9}{ }^{10}$ As with esophageal adenocarcinomas, Barrett's esophagus appears to be increasing in incidence. A recent study analyzing 11,028 patients in Denmark discovered the absolute annual risk of developing adenocarcinoma was $0.12 \%$, which is significantly less than previously thought. ${ }^{10}$ Similar to the relationship between colorectal cancer and adenomatous polyps, there is a distinct histological progression, with low grade and high grade dysplasia occurring before frank adenocarcinoma. This has encouraged the development of endoscopic screening programs for monitoring Barrett's esophagus, although their utility remains unclear. ${ }^{11}$

A strong positive correlation with lower socioeconomic status has been noted in studies of the incidence of esophageal cancer. As is so often the case, it is difficult to eliminate confounding factors, such as cigarette smoking, which are also associated with a lower socioeconomic status. ${ }^{12}$

In addition to the above risk factors, there are other putative factors that may increase the risk but are as yet insufficiently researched. These include opium consumption, hot drinks, drugs such as beta-adrenergic agonists and bisphosphonates, human papillomavirus, inadequate oral hygiene, and occupational hazards, such as silica or asbestos exposure. ${ }^{12,13}$ Various chemical carcinogens are also implicated in the development of esophageal cancer, for example, polycyclic aromatic hydrocarbons and N-nitroso compounds. These and many others are found in cigarette smoke, explaining in part at least the impressive carcinogenicity of the habit.

\section{Diagnosis and staging}

The majority of patients present with dysphagia or hematemesis, and thus the initial investigation is usually an upper gastrointestinal endoscopy which allows direct visualization of the lesion and multiple biopsies to be taken. If a barium swallow were the initial investigation identifying a lesion, a subsequent endoscopy would be required for histological diagnosis. Early lesions can appear as ulcers, nodules, or plaques, with more advanced lesions appearing as mass lesions which may be ulcerated or stenosing. The diagnostic accuracy improves with the number of biopsies taken, and at least six biopsies are advised. ${ }^{14,15}$ In Barrett's esophagus, multiple four quadrant biopsies at $2 \mathrm{~cm}$ intervals up the Barrett's segment increase diagnostic accuracy and 
improve the differentiation of high grade dysplasia from adenocarcinoma. ${ }^{16}$

Endoscopic developments such as high-resolution endoscopy, chromoendoscopy, narrow band imaging, and autofluorescence are increasingly being used to aid diagnosis. ${ }^{17}$ Accurate biopsy histopathology remains the gold standard for diagnosis. ${ }^{18}$

Following diagnosis, the staging of esophageal cancer uses the TNM system, assessing local infiltration through the layers of the esophageal wall and into surrounding tissues $(\mathrm{T})$, local lymph node metastases $(\mathrm{N})$, and distant metastases (M). The purpose is to determine the most appropriate treatment for each patient, and whether any intervention is likely to be curative or palliative. The 2010 edition of the TNM staging system of the American Joint Committee on Cancer (AJCC) and the Union for International Cancer Control for esophageal cancer differs from previous editions in that there are different stage groupings for squamous cell carcinomas and adenocarcinomas. ${ }^{19}$

The optimum investigations to score the malignancy comprise an initial computed tomography (CT) scan, endoscopic ultrasound (EUS), and fused CT and $2\left[{ }^{18} \mathrm{~F}\right]$ fluoro-2-deoxy-D glucose (FDG) positron emission tomography (PET/CT). EUS is used particularly to assess the depth of tissue invasion and metastases into regional and celiac lymph nodes, while PET/CT is used to detect metastases in distant tissues and lymph nodes.

A 2008 meta-analysis comparing EUS, CT, and PET individually demonstrated that regional lymph node metastases were detected with the most sensitivity by EUS, although CT and PET scans were far more specific. ${ }^{20}$ EUS was more sensitive and specific for celiac and abdominal lymph node metastases. There was no statistically significant difference between CT and PET scans individually for detection of distant metastases. A 2007 prospective study from The Netherlands examined the use of PET following extensive staging including CT and EUS-guided fine needle aspiration, and demonstrated that in a wide range of disease severity according to TNM stage and with the preceding tests, PET only upstaged the original diagnosis in 4\%. The authors were uncomfortable with the use of PET as routine in clinical practice, given the false positive rate of $7.5 \%$ and false negative rate of $4.5 \%$, recommending that it be used in more advanced cancers. ${ }^{21}$

Combined PET/CT imaging through two sequential scans aims to identify pathological uptake of glucose by tissues and the precise anatomical location. A UK-based cohort study of 191 patients examined the effect of PET/CT on staging versus CT and EUS alone. ${ }^{22}$ Staging was altered in $34 \%$ and subsequent management in $26 \%$ of cases, with a sensitivity of $91 \%$ and a specificity of $94 \%$. A similar study from Israel gave a sensitivity and specificity of $81 \%$ and $90 \%$, respectively. ${ }^{23}$ A retrospective study concerning the years 2001-2004 compared the efficacy in lymph node detection between a fusion of CT and PET and side-by-side CT and PET, and found no statistically significant difference, although the hybrid of CT and PET (PET/CT) had a higher sensitivity and sensitivity, both at $87 \%$ compared with $80 \%$ and $83 \%$, respectively. ${ }^{24}$

These imaging methods each have limitations. EUS only has a $5 \mathrm{~cm}$ penetration depth, CT scans are unable to detect lymph node metastases in normal-sized lymph nodes, and may give a false positive result in enlarged lymph nodes which are not attributable to malignant infiltration. FDG-PET is limited in recognizing lesions less than $1 \mathrm{~cm}$ in diameter or nodes adjacent to the primary tumor. ${ }^{20} \mathrm{CT} / \mathrm{PET}$ also has its limitations, including difficulty differentiating inflammatory changes from neoplastic ones in lymph node stations or lymphatic tissues. ${ }^{25}$ The UK cohort study demonstrated a false positive detection rate of $5 \%$, most frequently from increased uptake in the liver. ${ }^{22}$ One percent of the patients were reported falsely negative for metastases. This demonstrates the importance of multiple imaging investigations and the need for care in the use of PET/CT results in early disease, where a false positive would prevent the patient from receiving a potentially curative management strategy.

Prior to the latest edition of the AJCC staging guidelines, there was controversy over where tumors of the esophagogastric junction fit in the classification. Siewert and Stein in 1998 divided tumors occurring within $5 \mathrm{~cm}$ proximal and distal to the cardia into three types based on the anatomical location of the center of the lesion, ie, adenocarcinoma of the distal esophagus, true carcinoma of the cardia, and gastric carcinoma. ${ }^{26}$ A 2009 study compared the characteristics of tumors of the esophagogastric junction and those in the distal esophagus according to the Siewert classification, concluding that there was little difference in survival or recurrence post esophagectomy. ${ }^{27}$ The 7 th edition of AJCC staging guidelines now combines tumors with centers in the esophagus, esophagogastric junction, and proximal $5 \mathrm{~cm}$ of the stomach, a move supported by the existing data. ${ }^{19}$

\section{Management}

The management of esophageal cancer relies hugely on the staging discussed above. A multidisciplinary approach in units with sufficient throughput of patients is desirable, 
with surgery, gastroenterology, pathology, radiology, and palliative care involvement. The management of both localized and advanced cancer is controversial, with many previous studies combining different sites of esophageal tumor as well as histological type. With localized disease, the traditional approach of surgery as standard treatment is now recognized to be generally inferior to a multimodal approach. Management of tumors of the cervical esophagus is along the lines of that for head and neck squamous cell cancer, which is predominantly radiotherapy and will not be discussed further here.

\section{Surgery}

There have traditionally been two principal approaches in the surgical management of esophageal cancer, ie, the transhiatal esophagectomy and the transthoracic esophagectomy. The Ivor-Lewis transthoracic esophagectomy involves a laparotomy and right thoracotomy with an intrathoracic anastomosis, while the transhiatal esophagectomy involves an upper midline laparotomy and a left neck incision.

Modifications to these operations have been described in the literature, for example, the left transthoracic oesophagectomy and the tri-incisional esophagectomy, which is a modification of the McKeown technique combining the two above approaches, resulting in a transthoracic esophagectomy with a cervical anastomosis. ${ }^{28,29}$ These will not be discussed in detail here.

A comprehensive meta-analysis of English language literature comparing the two techniques is rather unhelpful in recommending one over the other. ${ }^{30}$ This was a meta-analysis of 52 studies comprising 5905 patients, excluding any surgery with the aim of palliation. The findings indicated that there was no significant difference in five-year survival between the two approaches.

Transthoracic esophagectomies were shown to retrieve a mean of eight more lymph nodes than transhiatal esophagectomies, although it was pointed out that only one of the 52 studies met the minimum recommended lymph node retrieval identified in a previous study since adopted by the AJCC in the 7 th edition of their cancer staging manual. ${ }^{31}$ The transthoracic esophagectomy was on average longer by 85 minutes, and required a hospital stay of four days longer than transhiatal esophagectomy, though there was no significant difference in blood loss between the two operations. No significant difference was seen between the two regarding the risk of cardiac complications, chyle leak, hemorrhage, pneumothorax, pleural effusion, acute lung injury, atelectasis, pulmonary embolism, and renal insufficiency.
The transthoracic esophagectomy was shown to have a higher early mortality in the first 30 days or during the hospital stay. It also had a higher rate of respiratory complications, although heterogeneity was significant. Transthoracic esophagectomy demonstrated a higher rate of pneumonia and wound infection with no significant heterogeneity. Transhiatal esophagectomy showed higher rates of anastomotic leaks, anastomotic strictures, and vocal cord paralysis, also without significant heterogeneity.

There was no difference in operative approach for tumors of the middle and lower esophagus, though it was noted that for those of the upper and cervical esophagus, transhiatal esophagectomy was performed more frequently. It was also noted that the transthoracic esophagectomy approach was more often used in advanced stages of esophageal cancer.

Although there seems to be a lot of useful information in this study, the overriding message of the conclusion is that the previous literature is insufficient to provide definitive guidance on the surgical management of esophageal cancer, specifically whether the transthoracic or the transhiatal approach should be preferred. The final conclusion of the authors was that although there was no demonstrable difference in 5-year survival, the quality of the information was such that this should not be wholly trusted. More robust studies in the future may give a clearer picture, but for now the evidence is not available. The article identified potentially misleading factors in the studies, for example the more advanced stages of cancer typically preferred for the transthoracic approach. One might expect a higher survival rate in the transthoracic esophagectomy group if this were accounted for.

The work of Rizk et al, among others, was instrumental in demonstrating that the number of involved lymph nodes was of more prognostic significance in the staging of esophageal cancer than anatomical location, resulting in the updated 7 th edition of the AJCC staging system. ${ }^{32}$ Eighteen lymph nodes was determined to be the minimum number required to be resected and analyzed, below which the disease was believed to be understaged.

Worldwide, there are different approaches to lymph node resections. Three-field lymph node dissection has traditionally been more prevalent in Japan, developed in response to reports of cervical lymph node metastases in esophageal squamous cell carcinoma following surgical resection. The relevance in the Western population has been questioned due to the increasing prevalence of adenocarcinoma and the increased risks this technique incurs. Altorki et al demonstrated the survival benefit of three-field lymph node 
dissection in a small study measuring the prevalence of cervical lymph node metastases in esophageal cancers. ${ }^{33}$ Importantly, the study showed that $36.25 \%$ of patients had metastases involving cervicothoracic nodes, seemingly independent of whether squamous cell carcinoma or adenocarcinoma, and also independent of tumor location within the esophagus.

A study from 2005 assessing the effect of lymphatic spread and tumor type demonstrated that in early (mucosal and submucosal spread) esophageal cancer, adenocarcinoma was associated with a better five-year survival of $83.4 \%$ compared with $62.9 \%$ for squamous cell carcinoma. ${ }^{34}$ Part of the decreased survival associated with squamous cell carcinoma may be due to the increased risk of lymphatic spread when compared with that of adenocarcinoma in this study. Esophageal squamous cell carcinoma also shows a more aggressive form of lymphatic spread, with less than $60 \%$ of involved lymph nodes in close proximity to the primary tumor compared with greater than $85 \%$ in esophageal adenocarcinoma. It was hypothesized that this might be explained by chronic inflammation associated with reflux in adenocarcinoma causing occlusion of the superficial lymphatic channels.

In practice, the surgical experience, tumor type and location, proposed lymphadenectomy, and patient factors determine the surgical approach. In general terms, patients with middle and upper third squamous tumors with lymphadenopathy may achieve more effective mediastinal lymphadenectomy from a transthoracic approach. In patients with distal adenocarcinoma, lymph node spread is more likely to be abdominal and hence the transhiatal approach may be more appropriate.

\section{Minimally invasive surgery}

Minimally invasive esophagectomies (MIE) are becoming increasingly popular, although there is still limited definitive evidence as to their efficacy. The technical difficulty of MIE has been well established, as has the large variety of differing approaches. There have been many trials which have typically been small in size, but comparison between them has proved difficult due to differing techniques, although reports are encouraging. At a single institution with considerable experience, Luketich et al reported good outcomes in a large 222 patient study, reporting a lower mortality rate $(1.4 \%)$ and a shorter hospital stay when compared with open esophagectomy. ${ }^{35}$

Complications of the laparoscopic approach are similar to those for open surgery, particularly anastomotic leak and pulmonary complications, such as pneumonia and atelectasis.
A prospective study in 2008 measuring short-term outcomes following MIE reported a postoperative morbidity of $47 \%$, including ischemic necrosis of the conduit, conduit leaks, pneumonia, chylothorax, and temporary vocal cord paresis. ${ }^{36}$ The majority of these patients were stage III adenocarcinomas. A retrospective study by Nafteux et al comparing MIE with open esophagectomy showed that there were fewer respiratory complications but an increased risk of gastrointestinal complications, particularly gastroparesis. ${ }^{37}$ Oncological outcome and 5-year recurrence-free survival were comparable.

Ideally, laparoscopic esophagectomy aims to minimize incisional pain, decreasing the risk of respiratory complications and reducing recovery time. A retrospective study by Bonavina et al in 2004 compared two groups, suggesting that in patients without liver metastases or gross nodal involvement noted on laparoscopy, a left cervicotomy was more effective in high risk patients and right thoracotomy in low risk T2-3 patients. ${ }^{38}$ They also discussed the use of videomediastinoscopy for visualizing endodissection of the upper thoracic esophagus compared with the blind dissection previously required. This is encouraging but a randomized controlled trial is required to validate their conclusions.

It is difficult to assess the prevalence of anastomotic leaks due to the differing definitions used by the various studies. It remains a high mortality complication. Respiratory complications appear to be higher compared with open esophagectomy, but again it is difficult to draw definite conclusions given the lack of standardization. ${ }^{39}$

A meta-analysis and systematic review of minimally invasive versus open esophagectomy showed that MIE appeared to have reduced mortality compared with open transthoracic esophagectomy, although there was no statistical significance. ${ }^{40}$ The authors concluded that although MIE appeared to provide few significant advantages other than a reduced hospital stay, the lack of randomized controlled trials comparing open and minimally invasive esophagectomies meant that very few conclusions could be drawn.

A randomized prospective study is preparing to compare an open approach using a right thoracotomy with MIE using right thoracoscopy. ${ }^{41}$ This should provide the best evidence of whether the use of MIE is comparable or even superior to the traditional open approach.

\section{Chemotherapy, radiotherapy, and chemoradiotherapy}

Considerable controversy surrounds the optimum use of chemotherapy and radiotherapy. Studies have often been 
difficult to interpret due to the fact that different tumor types and sites were not always distinguished. In a recent assessment of the various studies and meta-analyses relating to neoadjuvant chemoradiotherapy and chemotherapy, the contradictory nature of the evidence base was highlighted. ${ }^{42}$

The results of preoperative chemotherapy have been conflicting. There are two main studies supporting the use of neoadjuvant chemotherapy in the UK, ie, the Medical Research Council OEO2 and the MAGIC (Medical Research Council Adjuvant Gastric Infusional Chemotherapy) trials. The Medical Research Council OEO2 trial demonstrated that the use of preoperative chemotherapy led to improved survival without additional adverse effects when compared with surgical resection alone. ${ }^{43}$ The MAGIC trial demonstrated that preoperative chemotherapy and surgery led to a higher fiveyear survival compared with surgery alone in patients with adenocarcinoma of the stomach, esophagogastric junction, and lower esophagus. ${ }^{44}$ There are other trials that have demonstrated no benefit from neoadjuvant chemotherapy in the treatment of esophageal cancer. ${ }^{45,46}$

Neoadjuvant chemoradiotherapy is considered the preoperative treatment of choice in many countries, with several trials demonstrating an increased efficacy compared with surgery alone, with a $13 \%$ survival advantage at 2 years. ${ }^{47}$ However, this holds for both squamous and adenocarcinomas. In certain studies, the advantage was more pronounced in the squamous group, unlike that in preoperative chemotherapy, which seemed to favor adenocarcinoma. Drugs in most chemoradiotherapy regimes include a platinum agent such as cisplatin and a fluoropyrimidine such as 5-fluorouracil. ${ }^{42}$

In terms of adjuvant chemotherapy, the surgery-associated morbidity often makes chemotherapy inappropriate. In a meta-analysis of patients having adjuvant therapy, no survival advantage was seen. ${ }^{47}$

The use of chemoradiation as a definitive treatment in localized squamous cancer has been recommended and has the advantage over surgery/chemoradiation with regard to better reported quality of life in the short term, although quality of life at 1 and 2 years is comparable in comparative studies. ${ }^{48-50}$ In terms of survival benefit, there appears to be little difference and it has been advocated that surgery should be reserved for those with localized squamous tumors who have residual disease at the end of chemoradiation.

For adenocarcinoma, where surgery is inappropriate, usually due to comorbidity or patient choice, definitive chemoradiation is a valid approach. ${ }^{51}$ Preoperative radiotherapy alone in patients with resectable squamous or adenocarcinoma offers no significant benefit and is thus not recommended. ${ }^{52}$

\section{Screening and treatment of precursor lesions}

Patients investigated for upper gastrointestinal symptoms who are found to have Barrett's esophagus are increasingly being offered endoscopic screening, usually on a 2-yearly or 3 -yearly basis. The clinical benefit and cost-effectiveness of these programs is somewhat unclear, and recent data suggest that there needs to be risk stratification in determining the population to screen. ${ }^{11}$

The aim of these programs is to identify those patients at particularly high risk with low grade or high grade dysplasia or carcinoma in situ to allow intervention preventing the progression to invasive cancer. However, identification of dysplasia is problematic and has relied on multiple biopsies. New techniques such as chromoendoscopy, narrow band imaging, magnification endoscopy, and autofluorescence endoscopy may yet offer techniques to target areas of premalignant change rather than relying on random biopsies.

The traditional approach for those identified with high grade dysplasia has been oesophagectomy, but newer endoscopic techniques have been introduced with the aim of locally removing or destroying the neoplastic tissue and allowing regrowth of squamous mucosa. The techniques of endoscopic mucosal resection and dissection involve excising the abnormal mucosa and have the advantage of providing a histological specimen. Endoscopic mucosal resection has been successfully employed to remove localized early tumors with low morbidity and five-year disease-free survival of $95 \%$, with equivalent long-term survival when compared with surgery. ${ }^{53,54}$ Such procedures need to be carried out in high volume tertiary referral centers. ${ }^{55}$

Endoscopic mucosal resection essentially involves the very careful mapping of areas of dysplasia or carcinoma in situ followed by endoscopic excision of the tissue. A number of techniques have been employed. The most commonly used technique is to raise the lesion by injection into the submucosal layer. Using a transparent cap attached to the endoscope with an attached snare, the lesion is sucked into the cap, the snare employed, and the lesion resected by diathermy. An alternative technique without submucosal injection is to use a variceal ligation device to band the lesion which is then subsequently captured with a polypectomy snare. A development from the original banding technique is the multiband mucosectomy device which allows multiple resections without removal of the endoscope. Endoscopic mucosal resection by whichever technique is now the best minimally invasive therapy for high grade dysplasia and its effect lasts for several years. ${ }^{56,57}$ 
Treatment with high-dose proton pump inhibitors is advocated post procedure, and the ulcerated areas take 3-6 weeks to heal. The main complications are bleeding, stricture formation, and perforation.

Another technique which is widely used in the east, and now has some experts in the west is endoscopic mucosal dissection. This is technically more demanding and, as yet, large randomized comparisons of endoscopic mucosal resection have yet to be completed, but results from smaller studies are encouraging..$^{58}$

Photodynamic therapy, argon plasma coagulation, and radiofrequency ablation destroy the abnormal mucosa but do not provide a specimen, and may only have a limited depth of destruction. However, expert evidence published in a huge international consensus has indicated they are useful adjuncts to endoscopic mucosal resection. ${ }^{59}$

Photodynamic therapy relies on the principle that certain chemicals (photosensitizers) which are preferentially taken up by neoplastic tissue can be activated by light, producing a cytotoxic reaction by releasing oxygen radicals in the tissue which results in tissue necrosis. The current photosensitizers are either given intravenously or orally, and the light activation is provided by laser, ideally with a balloon diffuser, to give a more even distribution of light to the tissue. A study of 208 patients with Barrett's esophagus and high grade dysplasia demonstrated significant disease eradication in those treated with photodynamic therapy and omeprazole when compared with omeprazole alone ${ }^{60}$ A systematic review showed stricture formation in $18.5 \%$ of patients and development of photosensitivity in $26.4 \%$, and progression of high grade dysplasia to cancer has been shown to occur in $13 \%$ of patients. ${ }^{61}$ The technique is expensive and limited to a few centers at present.

Argon plasma coagulation ablation is a noncontact thermal electrocoagulation technique which involves the passing of an electrical current through argon gas into the tissue. A prospective study of 40 patients post fundoplication compared endoscopic surveillance with argon plasma coagulation. ${ }^{62}$ Complete ablation was achieved in $63 \%$ of those treated with argon plasma coagulation. Of 29 patients with high-grade dysplasia in a 2004 study, 22 showed complete regression. ${ }^{63}$ The mean duration of follow-up was 37 months. A comparison of argon plasma coagulation with photodynamic therapy showing that the two modalities had comparable efficacy. ${ }^{64}$ Complications have been shown to include perforation, stricture formation, and "buried" Barrett's glands, ie, metaplastic epithelium beneath the neosquamous epithelium. . $^{63,65,66}$
Radiofrequency ablation is a newer technique for mucosal ablation by which electrical energy delivered via an electrode array attached to the end of an endoscope destroys the mucosa. This can be delivered in a circumferential or focal manner. A multicenter sham-controlled trial demonstrated high rates of complete eradication of dysplasia $(90.5 \%, 81 \%$ of high grade dysplasia) and intestinal metaplasia (77.4\%) when compared with the sham procedure.$^{67}$ This study had a stricture rate of $6 \%$ (five patients), with one patient suffering from gastrointestinal hemorrhage and one patient from new-onset chest pain.

The above endoscopic resection and ablative techniques should be viewed as potentially complementary rather than alternative treatments. In practice, the technique preferred by each center depends on local expertise and resources. Endoscopic mucosal resection is the most generally available technique and currently forms the mainstay of managing high grade dysplasia. Radiofrequency ablation, argon plasma coagulation, and photodynamic therapy are evolving techniques not as yet established or available as endoscopic mucosal resection. Their future role in managing precursor lesions is unclear.

\section{Palliative treatment}

As discussed above, the majority of patients unfortunately present with advanced local disease so that noncurative palliative treatment is the treatment goal. Palliative treatment may also be the only option for those unfit for curative surgery or refusing surgery. In terms of palliation, symptomatic control of dysphagia, pain, and bleeding are the major issues. Significant dysphagia clearly affects nutrition, but also is a major psychosocial issue, setting the patient apart from family and friends in terms of eating and socializing.

Surgical palliation plays no role here because the life expectancy of these patients is limited, and the morbidity and mortality of a surgical procedure is high compared with other interventions. The palliative options include radiotherapy, chemotherapy, and local treatments such as dilatation, stenting, laser. and photodynamic therapy. Often multiple approaches are required to improve quality of life, but the sustainability of this improvement may be quite variable.

The standard chemotherapy regimen for palliation of unresectable esophagogastric cancer for many years was epirubicin, cisplatin, and fluorouracil. ${ }^{68,69}$ However, more recently, capecitabine and oxaliplatin have been shown to be as effective as fluorouracil and cisplatin, with capecitabine showing an admittedly nonsignificant 
trend towards improved survival. ${ }^{70}$ Capecitabine has the advantage of oral administration compared with the necessity for intravenous infusion of fluorouracil. Capecitabine was also assessed by the National Institute of Clinical Excellence as more cost-effective in the guidelines for gastric cancer. ${ }^{71}$ The recommended regimens are either epirubicin, oxaliplatin, and capecitabine, or epirubicin, cisplatin, and capecitabine. ${ }^{72}$

External beam radiotherapy alone has been used to palliate dysphagia but offers little chance of prolonged palliation. ${ }^{73}$ In combination with chemotherapy, the results are far superior in those patients fit enough for it. ${ }^{74}$ The downsides of this approach relate to the external beam radiotherapy taking a number of weeks to complete and thus the patient's decision regarding potential benefits and life expectancy becomes very important. Two complications of radiotherapy are the development of a benign stricture which can usually be managed by balloon dilatation, and a tracheo-esophageal fistula. This latter complication is a serious development which can, of course, develop spontaneously with the tumor, as well as being associated with radiotherapy. The most effective treatment is the employment of a covered metal stent (see below).

Simple endoscopic balloon dilatation can provide some alleviation of dysphagia but alone is only going to give very temporary relief, although the procedure has a lower rate of complications than stent placement. ${ }^{75}$ Covered selfexpanding metal stents can be employed endoscopically and can be effective in providing quick-acting and long-term relief from dysphagia. ${ }^{76}$ However, they are of little use in the upper esophagus and in one study were associated with complications necessitating further intervention in more than $50 \%$ of patients. ${ }^{77}$

Neodymium-yttrium-aluminum-garnet (Nd:YAG) laser offers a method of fulgurating tumor tissue and is especially useful in exophytic tumors, particularly in the mid and distal esophagus. ${ }^{78}$ The disadvantages are the risk of perforation $(5 \%)$, cost, and frequency of treatments. A low-cost alternative is injection of absolute alcohol, although experience with this is limited. ${ }^{79}$ More sophisticated techniques that have been tried include injection of cisplatin/epinephrine gel into the tumor, argon plasma coagulation, and brachytherapy with the insertion of a radioactive source adjacent to the tumor. $^{80-82}$ More recently, photodynamic therapy has been used (discussed above). Initial reports suggest this technique may be more effective than using laser. ${ }^{83}$ In practice, most units use what they have available and what they have expertise in. This usually means esophageal stenting.

\section{Prevention of esophageal cancer}

Clearly control of environmental factors is important in the prevention of esophageal cancer, probably accounting for the increasing rate of esophageal adenocarcinoma. Reflux is a major factor and increasing obesity rates may well be important. Smoking is also pertinent and is of course already being targeted for its effects in cardiovascular disease and lung neoplasia. The evidence for the treatment of reflux in reducing cancer risk is lacking, but is the focus of ongoing studies. As with colorectal cancer, there is interest in whether aspirin can reduce the risk of esophageal cancer. The results of AspECT (the Aspirin Esomeprazole Chemoprevention Trial) looking at the effect of proton pump inhibitor and aspirin treatment on the progression of Barrett's esophagus are awaited with interest. ${ }^{84}$

\section{Conclusion}

Cancer of the esophagus remains a lethal tumor, with little improvement in overall survival over the past 30 years. ${ }^{85}$ This dismal picture almost certainly relates to a combination of tumor biology with early malignant cell dissemination and the fact that the tumors only present late in their natural history, when they are large and causing symptoms of mechanical obstruction. Advances in multimodal treatment and palliative approaches have been significant. An increased focus on treatment enhancing quality of life in patients with such a poor prognosis is required.

The steady increase in esophageal adenocarcinomas represents a major challenge and suggests that we need to concentrate on etiological factors such as reflux, obesity, and Barrett's esophagus which we may be able to modify. ${ }^{86}$ There has been a recent huge systematic review with 92 international experts indicating that good quality endoscopes are important for Barrett's surveillance, access and training in endoscopic mucosal resection are essential for patient management, and, finally, use of radiofrequency ablation to ablate residual Barrett's precautionary. ${ }^{60}$ However, there needs to be a significant investment in studying primary prevention, identifying, and screening high risk groups and the optimal management of precursor lesions, ie, "cure is good but prevention is even better".

\section{Disclosure}

The authors report no conflicts of interest in this work.

\section{References}

1. Jemal A, Center MM, DeSantis C, Ward EM. Global patterns of cancer incidence and mortality rates and trends. Cancer Epidemiol Biomarkers Prev. 2010;19(8):1893-1907. 
2. Jemal A, Bray F, Center MM, Ferlay J, Ward E, Forman D. Global cancer statistics. CA Cancer J Clin. 2011;61(2):69-90.

3. Gatenby P, Hainsworth A, Caygill C, Watson A, Winslet M. Projections for oesophageal cancer incidence in England to 2033. Eur J Cancer Prev. 2011;20(4):283-286.

4. Hesketh PJ, Clapp RW, Doos WG, Spechler SJ. The increasing frequency of adenocarcinoma of the esophagus. Cancer. 1989;64(2):526-530.

5. Steevens J, Schouten LJ, Goldbohm RA, van den Brandt PA. Alcohol consumption, cigarette smoking and risk of subtypes of oesophageal and gastric cancer: a prospective cohort study. Gut. 2010;59(1):39-48.

6. Zendehdel K, Nyren O, Edberg A, Ye W. Risk of esophageal adenocarcinoma in achalasia patients, a retrospective cohort study in Sweden. Am J Gastroenterol. 2011;106(1):57-61.

7. Gordon C, Kang JY, Neild PJ, Maxwell JD. The role of the hiatus hernia in gastro-oesophageal reflux disease. Aliment Pharmacol Ther. 2004;20(7):719-732.

8. Barrett NR. Chronic peptic ulcer of the oesophagus and 'oesophagitis'. Br J Surg. 1950;38(150):175-182.

9. Jankowski J, Barr H, Wang K, Delaney B. Diagnosis and management of Barrett's oesophagus. BMJ. 2010;341:c4551.

10. Hvid-Jensen F, Pedersen L, Drewes AM, Sørensen HT, Funch-Jensen P. Incidence of adenocarcinoma among patients with Barrett's esophagus N Engl J Med. 2011;365(15):1375-1383.

11. Kahrilas PJ. The problems with surveillance of Barrett's esophagus. N Engl J Med. 2011;365(15):1437-1438.

12. Kamanger F, Chow WH, Abnet CC, Dawsey SM. Environmental causes of esophageal cancer. Gastoenterol Clin North Am. 2009;38(1): 27-57, vii.

13. Cardwell CR, Abnet CC, Cantwell MM, Murray LJ. Exposure to oral bisphosphonates and risk of esophageal cancer. JAMA. 2010;304(6):657-663.

14. Graham DY, Schwartz JT, Cain GD, Gyorkey F. Prospective evaluation of biopsy number in the diagnosis of esophageal and gastric carcinoma. Gastroenterology. 1982;82(2):228.

15. Lal N, Bhasin DK, Malik AK, Gupta NM, Singh K, Mehta SK. Optimal number of biopsy specimens in the diagnosis of carcinoma of the oesophagus. Gut. 1992;33(6):724-726.

16. Levine DS, Haggitt RC, Blount PL, Rabinovitch PS, Rusch VW, Reid BJ. An endoscopic biopsy protocol can differentiate highgrade dysplasia from early adenocarcinoma in Barrett's esophagus. Gastroenterology. 1993;105(1):40-50.

17. Curvers WL, Singh R, Wong-Kee Song L-M, et al. Endoscopic trimodal imaging for detection of early neoplasia in Barrett's oesophagus: a multi-centre feasibility study using high-resolution endoscopy, autofluorescence imaging and narrow band imaging incorporated in one endoscopy system. GAm J Gastroenterol. 2009;104(5):1093-1096.

18. Jankowski JA, Odze RD. Biomarkers in gastroenterology: between hope and hype comes histopathology. Am J Gastroenterol. 2009;104(5): 1093-1096.

19. Edge SB, Byrd DR, Compton CC, Fritz AG, Greene FL, Trotti A, editors. AJCC Cancer Staging Manual. 7th ed. New York, NY: SpringerVerlag; 2010

20. van Vliet, Heijenbrok-Kal MH, Hunink MGM, Kuipers EJ, Siersema PD Staging investigations for oesophageal cancer: a meta-analysis. Br J Cancer. 2008;98(3):547-557.

21. van Westreenen HL, Westerterp M, Sloof GW, et al. Limited additional value of positron emission tomography in staging oesophageal cancer. Br J Surg. 2007;94(12):1515-1520.

22. Noble F, Bailey D, Tung K, Byrne JP. Impact of integrated PET/CT in the staging of oesophageal cancer - a UK population-based cohort study. Clin Radiol. 2009;64(7):699-705.

23. Bar-Shalom R, Guralnik L, Tsalic M, et al. The additional value of PET/CT over PET in FDG imaging of oesophageal cancer. Eur J Nucl Med Mol Imaging. 2005;32(8):918-924.

24. Kato H, Kimura H, Nakajima M, et al. The additional value of integrated PET/CT over PET in initial lymph node staging of esophageal cancer. Oncol Rep. 2008;20(4):857-862.
25. Kostakoglu L, Hardoff R, Mirtcheva R, Goldsmith SJ. PET-CT fusion imaging in differentiating physiologic from pathologic FDG uptake. Radiographics. 2004;24(5):1411-1431.

26. Siewert JR, Stein HJ. Classification of adenocarcinoma of the oesophagogastric junction. Br J Surg. 1998;85(11):1457-1459.

27. Leers JM, DeMeester SR, Chan N, et al. Clinical characteristics, biologic behavior, and survival after esophagectomy are similar for adenocarcinoma of the gastroesophageal junction and the distal esophagus. J Thorac Cardiovasc Surg. 2009;138(3):594-602.

28. Krasna MJ. Left transthoracic esophagectomy. Chest Surg Clin N Am. 1995;5(3):543-554.

29. Swanson SJ, Baritel HF, Bueno R, et al. Transthoracic esophagectomy with radical mediastinal and abdominal lymph node dissection and cervical esophagogastrostomy for esophageal carcinoma. Ann Thorac Surg. 2002;72(6):1918-1924.

30. Boshier PR, Anderson O, Hanna GB. Transthoracic versus transhiatal esophagectomy for the treatment of esophagogastric cancer: a meta-analysis. Ann Surg. 2011;254(6):894-906.

31. Rizk NP, Ishwaran H, Rice TW, et al. Optimum lymphadenectomy for esophageal cancer. Ann Surg. 2010;251(1):46-50.

32. Rizk N, Venkatraman E, Park B, et al. The prognostic importance of the number of involved lymph nodes in esophageal cancer: implications for revisions of the American Joint Committee on Cancer staging system. J Thorac Cardiovasc Surg. 2006;132(6):1374-13781.

33. Altorki N, Kent M, Ferrara C, Port J. Three-field lymph node dissection for squamous cell and adenocarcinoma of the esophagus. Ann Surg. 2002;236(2):177-183.

34. Stein HJ, Feith M, Bruecher BL, Naehrig J, Sarbia M, Siewert JR. Early esophageal cancer: pattern of lymphatic spread and prognostic factors for long-term survival after surgical resection. Ann Surg. 2005;242(4):566-573.

35. Luketich JD, Alvelo-Rivera M, Buenaventura PO, et al. Minimally invasive esophagectomy: outcomes in 222 patients. Ann Surg. 2003;238(4):486-494.

36. Berrisford RG, Wajed SA, Sanders D, Rucklidge MW. Short-term outcomes following total minimally invasive oesophagectomy. $\mathrm{Br} \mathrm{J}$ Surg. 2008;95(5):602-610.

37. Nafteux P, Moons J, Coosemans W, et al. Minimally invasive oesophagectomy: a valuable alternative to open oesophagectomy for the treatment of early oesophageal and gastro-oesophageal junction carcinoma. Eur J Cardiothorac Surg. 2011;40(6):1455-1464.

38. Bonavina L, Bona D, Binyom PR, Peracchia A. A laparoscopyassisted surgical approach to esophageal carcinoma. J Surg Res. 2004;117(1):52-57.

39. Butler N, Collins S, Memon B, Memon MA. Minimally invasive oesophagectomy: current status and future direction. Surg Endosc. 2011;25(7):2071-2083.

40. Biere SS, Cuesta MA, van der Peet DL. Minimally invasive versus open esophagectomy for cancer: a systematic review and meta-analysis. Minerva Chir. 2009;64(2):121-133.

41. Biere SS, Maas KW, Bonavina L, et al. Traditional invasive vs minimally invasive esophagectomy: a multi-centered, randomized trial (TIME-trial). BMC Surg. 2011;11(1):2.

42. Hingorani M, Crosby T, Maraveyas A, Dixit S, Bateman A, Roy R. Neoadjuvant chemoradiotherapy for resectable oesophageal and gastrooesophageal junction cancer - do we need another randomised trial? Clin Oncol. 2011;23(10):696-705.

43. Medical Research Council Oesophageal Cancer Working Group. Surgical resection with or without preoperative chemotherapy in oesophageal cancer: a randomised controlled trial. Lancet. 2002; 359(9319):1727-1733

44. Cunningham D, Allum WH, Stenning SP, et al. Perioperative chemotherapy versus surgery alone for resectable gastroesophageal cancer. $N$ Engl J Med. 2006;355(1):11-20.

45. Kelsen DP, Ginsberg R, Pajak TF, et al. Chemotherapy followed by surgery compared with surgery alone for localized esophageal cancer N Engl J Med. 1998;339(27):1979-1984. 
46. Malthaner RA, Wong RK, Rumble RB, Zuraw L; Members of the Gastrointestinal Cancer Disease Site Group of Cancer Care Ontario's Program in Evidence-based Care. Neoadjuvant or adjuvant therapy for resectable esophageal cancer: a systematic review and meta-analysis. BMC Med. 2004;2:35.

47. Gebski V, Burmeister B, Smithers BM, et al. Survival benefits from neoadjuvant chemoradiotherapy or chemotherapy in oesophageal carcinoma: a meta-analysis. Lancet Oncol. 2007;8(3):226-234.

48. Bedenne L, Michel P, Bouche O, et al. Chemoradiation followed by surgery compared with chemoradiation alone in squamous cancer of the esophagus: FFCD 9102. J Clin Oncol. 2007;25(10): $1160-1168$.

49. Bonnetain F, Bouche O, Michel P, et al. A comparative longitudinal quality of life study using the Spitzer quality of life index in a randomized multicenter phase III trial (FFCD 9102): chemoradiation followed by surgery compared with chemoradiation alone in locally advanced squamous resectable thoracic esophageal cancer. Ann Oncol. 2006;17(5):827-834.

50. Avery KN, Metcalfe C, Barham CP, et al. Quality of life during potentially curative treatment for locally advanced oesophageal cancer. $\mathrm{Br} J$ Surg. 2007;94911:1369-1376.

51. Anderson SE, Minsky BD, Bains M, et al. Combined modality chemoradiation in elderly oesophageal cancer patients. $\mathrm{Br}$ J Cancer. 2007;96(12):1823-1827.

52. Arnott SJ, Duncan W, Gignoux M, et al. Preoperative radiotherapy for esophageal carcinoma. Cochrane Database Syst Rev. 2005;4:CD001799.

53. Ciocirlan M, Lapalus MG, Hervieu V, et al. Endoscopic mucosal resection for squamous premalignant and early malignant lesions of the esophagus. Endoscopy. 2007;39(1):24-29.

54. Das A, Singh V, Fleischer DE, Sharma VK. A comparison of endoscopic treatment and surgery in early esophageal cancer: an analysis of surveillance epidemiology and end results data. Am J Gastroenterol. 2008;103(6):1340-1345.

55. National Institute for Health and Clinical Excellence. Endoscopic submucosal dissection of oesophageal dysplasia and neoplasia. IPG355. London, UK: National Institute for Health and Clinical Excellence; 2010.

56. Shaheen NJ, Sharma P, Overholt BF, et al. Radiofrequency ablation in Barrett's esophagus with dysplasia. N Engl J Med. 2009;360(22): 2277-2288

57. Shaheen NJ, Overholt BF, Sampliner RE, et al. Durability of radiofrequency ablation in Barrett's esophagus with dysplasia. Gastroenterology. 2011;141(2):460-468.

58. Takahashi H, Arimura Y, Masao H, et al. Endoscopic submucosal dissection is superior to conventional endoscopic resection as a curative treatment for early squamous cell carcinoma of the esophagus (with video). Gastrointest Endosc. 2010;72(2):255-264.

59. Overholt BF, Wang KK, Burdick JS, et al. Five-year efficacy and safety of photodynamic therapy with Photofrin in Barrett's high-grade dysplasia. Gastrointest Endosc. 2007;66(3):460-468.

60. Bennett C, Vakil N, Bergman J, et al. Consensus statements for management of barrett's dysplasia and early-stage esophageal adenocarcinoma, based on a Delphi process. Gastroenterology. 2012; 143(2):336-346.

61. Overholt BF, Lightdale CJ, Wang KK, et al. Photodynamic therapy with porfimer sodium for ablation of high-grade dysplasia in Barrett's esophagus: international, partially blinded, randomized phase III trial. Gastrointest Endosc. 2005;62(4):488-498.

62. Ackroyd R, Tam W, Schoeman M, Devitt PG, Watson DI. Prospective randomized controlled trial of argon plasma coagulation ablation vs endoscopic surveillance of patients with Barrett's esophagus after antireflux surgery. Gastrointest Endosc. 2004;59(1):1-7.

63. Attwood SE, Lewis CJ, Caplin S, Hemming K, Armstrong G. Argon beam plasma coagulation as therapy for high-grade dysplasia in Barrett's esophagus. Clin Gastroenterol Hepatol. 2003;1(4):258-263.
64. Ragunath K, Krasner N, Raman VS, Haqqani MT, Phillips CJ, Cheung I. Endoscopic ablation of dysplastic Barrett's oesophagus comparing argon plasma coagulation and photodynamic therapy: a randomized prospective trial assessing efficacy and cost-effectiveness. Scand $J$ Gastroenterol. 2005;40(7):750-758.

65. Rees JR, Lao-Sirieix P, Wong A, Fitzgerald RC. Treatment for Barrett's oesophagus. Cochrane Database Syst Rev. 2010;1:CD004060.

66. Conio M, Cameron AJ, Chak A, Blanchi S, Filiberti R. Endoscopic treatment of high-grade dysplasia and early cancer in Barrett's oesophagus. Lancet Oncol. 2005;6(5):311-321.

67. Shaheen NJ, Sharma P, Overholt BF, et al. Radiofrequency ablation in Barrett's esophagus with dysplasia. $N$ Engl J Med. 2009;360(22): 2277-2288.

68. Webb A, Cunningham D, Scarffe JH, et al. Randomized trial comparing epirubicin, cisplatin, and fluorouracil versus fluorouracil, doxorubicin, and methotrexate in advanced esophagogastric cancer. J Clin Oncol. 1997;15(1):261-267.

69. Waters JS, Norman A, Cunningham D, et al. Long-term survival after epirubicin, cisplatin and fluorouracil for gastric cancer: results of a randomized trial. Br J Cancer. 1999;80(1-2):269-272.

70. Cunningham D, Starling N, Rao S, et al. Capecitabine and oxaliplatin for advanced esophagogastric cancer. $N$ Engl J Med. 2008;358(1): $36-46$.

71. National Institute for Health and Clinical Excellence. Capecitabine for the treatment of advanced gastric cancer. TA191. London, UK: National Institute for Health and Clinical Excellence; 2010.

72. Allum WH, Blazeby JM, Griffin SM, et al. Guidelines for the management of oesophageal and gastric cancer. Gut. 2011;60(11):1449-1472.

73. al-Sarraf M, Martz K, Herskovic A, et al. Progress report of combined chemoradiotherapy versus radiotherapy alone in patients with esophageal cancer: an intergroup study. J Clin Oncol. 1997;15(1): 277-284.

74. O’Rourke IC, Tiver K, Bull C, Gebski V, Langlands AO. Swallowing performance after radiation therapy for carcinoma of the esophagus. Cancer. 1988;61(10):2022-2026.

75. Kim JH, Song HY, Shin JH, et al. Palliative treatment of unresectable esophagogastric junction tumors: balloon dilation combined with chemotherapy and/or radiation therapy and metallic stent placement. J Vasc Interv Radiol. 2008;19(6):912-917.

76. Madhusudhan C, Saluja SS, Pal S, et al. Palliative stenting for relief of dysphagia in patients with inoperable esophageal cancer: impact on quality of life. Dis Esophagus. 2009;22(4):331-336.

77. Homann N, Noftz MR, Klingenberg-Noftz RD, Ludwig D. Delayed complications after placement of self-expanding stents in malignant esophageal obstruction: treatment strategies and survival rate. Dig Dis Sci. 2008;53(2):334-340.

78. Haddad NG, Fleischer DE. Endoscopic laser therapy for esophageal cancer. Gastrointest Endosc Clin N Am. 1994;4(4):863-874.

79. Chung SC, Leong HT, Choi CY, Leung JW, Li AK. Palliation of malignant oesophageal obstruction by endoscopic alcohol injection. Endoscopy. 1994;26(3):275.

80. Harbord M, Dawes RF, Barr H, et al. Palliation of patients with dysphagia due to advanced esophageal cancer by endoscopic injection of cisplatin/ epinephrine injectable gel. Gastrointest Endosc. 2002;56(5):644.

81. Eriksen JR. Palliation of non-resectable carcinoma of the cardia and oesophagus by argon beam coagulation. Dan Med Bull. 2002;49(4):346-349.

82. Wenger $\mathrm{U}$, Johnsson E, Bergquist $\mathrm{H}$, et al. Health economic evaluation of stent or endoluminal brachytherapy as a palliative strategy in patients with incurable cancer of the oesophagus or gastro-oesophageal junction: results of a randomized clinical trial. Eur J Gastroenterol Hepatol. 2005;17(12):1369-1377.

83. Lightdale CJ, Heier SK, Marcon NE, et al. Photodynamic therapy with porfimer sodium versus thermal ablation therapy with Nd:YAG laser for palliation of esophageal cancer: a multicenter randomized trial. Gastrointest Endosc. 1995;42(6):507-512. 
84. Das D, Chilton AP, Jankowski JA. Chemoprevention of oesophageal cancer and the AspECT trial. Recent Results Cancer Res. 2009;181 161-169.

85. Jemal A, Siegel R, Xu J, Ward E. Cancer statistics, 2010. CA Cancer J Clin. 2010;60(5):277-300.
86. Lund O, Hasenkam JM, Aagaard MT, Kimose HH. Time-related changes in characteristics of prognostic significance in carcinomas of the oesophagus and cardia. Br J Surg. 1989;76(12):1301-1307.

\section{Publish your work in this journal}

Gastrointestinal Cancer: Targets and Therapy is an international, peer-reviewed, open access journal focusing on gastro-intestinal cancer research, identification of therapeutic targets and the optima use of preventative and integrated treatment interventions to achieve improved outcomes, enhanced survival and quality of life for the cancer patient. The manuscript management system is completely online and includes a very quick and fair peer-review system. Visit http://www.dovepress.com/testimonials.php to read real quotes from published authors.

Submit your manuscript here: http://www.dovepress.com/gastro-intestinal-cancer-targets-and-therapy-journal 